\title{
The urban heat island in Salamanca (Spain) and its relationship to meteorological parameters
}

\author{
M. S. Alonso*, M. R. Fidalgo, J. L. Labajo \\ Department of General and Atmospheric Physics, University of Salamanca, 37008 Salamanca, Spain
}

\begin{abstract}
An urban heat island (UHI) was found to exist in Salamanca, Spain-a medium-sized European city that has a continental climate and relatively little industrial pollution. We demonstrate that urban heating can occur in cities with these characteristics, giving rise to a microclimate that may alter the biological rhythm of the zone e.g. under these conditions, spring arrives earlier in the urban zone then in the rural zone. The study was carried out using data from 2 recording stations (one in and the other outside the city) for the years 1996-1998. The existence of a nocturnal UHI was observed, with a highest annual mean value of $3.6^{\circ} \mathrm{C}$ and a lowest annual mean value (cool island) of $-0.9^{\circ} \mathrm{C}$. The most intense nocturnal UHI was seen in autumn, while the strongest sinks occurred in spring and summer. As in other types of city with different characteristics, the UHI was seen to vary according to the atmospheric situation. The meteorological variables that most affected the UHI were found to be: (1) wind, which at speeds of $>\sim 6 \mathrm{~m} \mathrm{~s}^{-1}$ prevented the development of UHIs; (2) cloudiness, which altered the flux of incident solar radiation (the intensity of the nocturnal UHI was greater with high clouds); and (3) atmospheric pressure, which characterised the days of atmospheric stability or instability, leading to variations in the intensity of the UHI.
\end{abstract}

KEY WORDS: Urban heat island · Local climate · UHI sink · Wind · Cloudiness · Synoptic conditions · Salamanca

Resale or republication not permitted without written consent of the publisher

\section{INTRODUCTION}

At small scales, human activity is of crucial importance with regard to the behaviour of climate factors, generating artificial microclimates. The most important manifestation of the impact of urbanisation on the climate is the difference in temperature between cities and their surrounding rural zones, known as the 'urban heat island' (UHI). The effects of human activity on the UHI range from air pollution to modifications of local climatic characteristics, and pose potentially serious consequences for social welfare. The larger the city in question, the more important the UHI (López et al. 1993). Accordingly, most studies have been carried out on fairly large cities throughout the world, especially those strongly affected by air pollution (Landsberg 1981, Saitoh \& Hoshi 1992).

Sometimes, the UHI phenomenon may alter the regional climate, causing a decrease in the number of days with frosts and increasing the distance of the snow limit from the city. Repercussions on biological processes are also important since UHIs may decrease the length of the cold period in cities; this means that the climatic characteristics of spring appear earlier, e.g. flowering occurs earlier in city parks and gardens than for the same species in nearby rural areas, while the climatic characteristics of autumn are delayed. Additionally, a UHI in a city may lead to decreases in the use of heating systems in winter and increases in the use of air conditioning systems in summer (López et al. 1993).

Radiative processes play a very important role in the generation of thermal contrasts between neighbouring zones (Hänel et al. 1990). Although there is often a local greenhouse effect caused by atmospheric pollution, which reduces the amount of solar radiation reaching the ground, a combination of opposing factors often create a temperature difference between the city and the surrounding rural area. Urban heating 
mainly derives from the absorption of the solar radiation that reaches the ground and buildings from dawn until the sun reaches its maximum height. When the sun's radiation reaches buildings, the ensuing successive reflections lead to more energy being confined within their sphere of influence than in rural settings (Wilby 2003). Materials forming the surface of cities usually have a greater heat absorption capacity than natural soils, so that in urban zones the energy is stored for longer than in rural zones (Hoyano et al. 1999). In turn, long-wave radiation coming from the ground is less able to cross the pollution layer, thus further contributing to heating the urban zone.

Meteorological factors also alter the energy balance existing between the ground and the top of the atmosphere. For example, wind causes turbulence that homogenises the air temperature (Jáuregui 1988, Morris \& Simmonds 2000), and clouds absorb or reflect solar radiation, thereby varying the amount of radiation that reaches the ground (Labajo et al. 1988).

Following the results of a pioneer study by Sundborg (1950) into the temperature conditions of an urban zone; and those of Morris \& Simmons (2000) and Morris et al. (2001) who related the intensity of an UHI to meteorological factors, we were prompted to determine the existence of a UHI in a mediumsized European city and to analyse the temporal evolution of its intensity and its relationship to meteorological variables. To conduct the study, we chose the city of Salamanca (Spain), located on the northern plateau of the Iberian Peninsula $\left(40^{\circ} 55^{\prime} \mathrm{N}, 5^{\circ} 28^{\prime} \mathrm{W}\right)$, at a height of $800 \mathrm{~m}$ above sea level (Fig. 1). The population of the city is about 190000 ; it is subject to a continental climate and receives little industrial pollution, most air pollution being from traffic and central heating system emissions (Fidalgo et al. 1988). Throughout the year, the synoptic atmospheric situation is more stable than unstable since the city is frequently under the influence of the Azores anticyclone. Despite this, the climate of Salamanca can be considered extreme, with annual thermal fluctuations of up to $40^{\circ} \mathrm{C}$, giving rise to very cold winters and very hot summers. Most precipitation falls in autumn and spring, while the summers are dry (La Porte \& Labajo 1983, Fidalgo 1994).

This is the first time that the UHI effect has been studied in this part of Spain. Previous studies have focused on Madrid (López et al. 1993), Barcelona (Moreno-García 1994), and Granada (Montávez et al 2000). The data and methods used in the study are described in Section 2. The evolution of the Salamanca UHI over time, diurnally, seasonally and from yearto-year is discussed in Section 3, while its relationships to meteorological factors are explored in Section 4. Conclusions are presented in Section 5.

\section{DATA AND METHODS}

The method used involved a comparison of the temperature data series obtained from weather stations located at urban and rural points, as has been used in a number of other studies (García 1996, Sahashi \& Hieda 1996, Figuerola \& Mazzeo 1998, Unger et al. 2001, Kim \& Baik 2002, Alonso et al. 2003). The first step in a study of this type is to select reliable weather stations in zones with representative characteristics; e.g. rural measuring stations should be situated outside the sphere of influence of the city.

The intensity $(I)$ of the UHI was calculated as the difference between the urban mean temperature $\left(T_{\mathrm{u}}\right)$ and the rural mean temperature $\left(T_{\mathrm{r}}\right)\left(I=T_{\mathrm{u}}-T_{\mathrm{r}}\right)$ at the climatological (i.e. synoptic) hours 00:00, 07:00, 13:00 and 18:00 h UTC. Following this, a statistical study was performed, which first considered the mean and extreme values of $I$ in order to establish the range of values between which the intensity of the UHI fluctuated. This was done considering the different hours of the day or periods of the year separately. The annual evolution of the UHI was established using a monthby-month study, which in turn allowed the determination of its range of intensity.

The relationship between the intensity of the UHI and meteorological factors was established using simple linear regressions, making an analysis of the correlation matrix. Plotting the joint evolutions of the intensity of the UHI and the meteorological factors helped to visualise the relationships found.

The data corresponding to the rural setting were those measured at the weather station of the observatory network of the Instituto Nacional de Meterologìa (INM) located at Matacán (altitude $790 \mathrm{~m}$ ). This station is considered to be 'rural' because it is sufficiently dis-

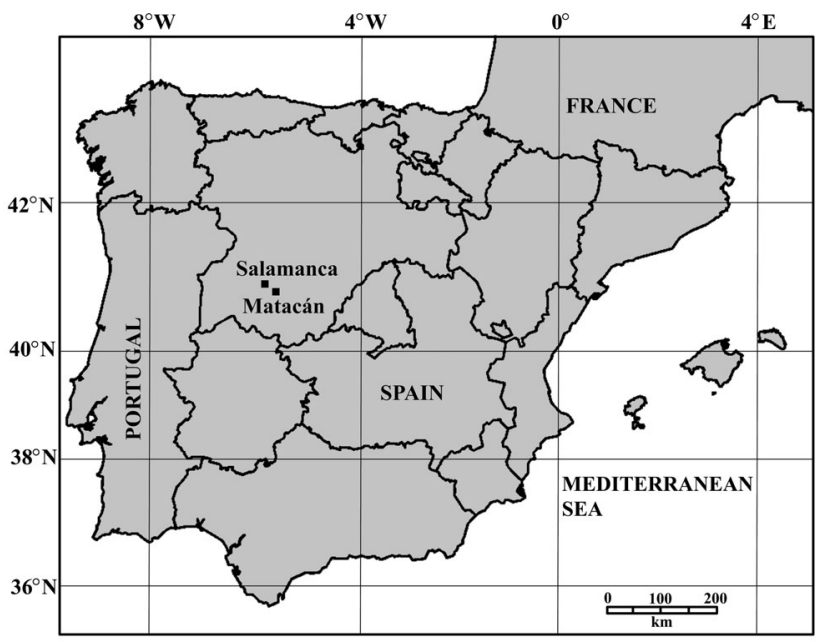

Fig. 1. Location of the urban (Salamanca) and rural (Matacán) study stations 
tant from the city $(16 \mathrm{~km})$ and is in a green area. In the urban setting, the station 'E1' was used, which is located in the heart of the city amid heavy traffic and a high density of buildings. The E1 recording station forms part of the atmospheric surveillance and control network of the regional community of Castilla y León.

For the urban station, the temperature data corresponding to those taken at 00:00, 07:00, 13:00 and 18:00 h UTC were used in order to be able to make direct comparisons with the rural station at Matacán, which makes measurements at these climatological hours. Data on the intensity of the heat island at daily maximum and minimum temperatures were also considered (maximum and minimum temperatures occur at almost the same time at the rural and urban stations). The study was carried out over a 3 yr period (1996 to 1998).

\section{EVOLUTION OVER TIME}

\subsection{Daily evolution}

The daily evolution of the intensity $(I)$ of the UHI over a 1 yr period (1996) was analysed first. The intensity of the UHI was calculated for the daytime: 13:00 and 18:00 $\mathrm{h} \mathrm{UTC}$, and at the hour of maximum temperature $\left(I_{\max }\right)$; and for the nighttime: 00:00 and 07:00 $\mathrm{h}$ UTC, and at the hour of minimum temperature $\left(I_{\min }\right)$, because the initial conditions are dependent on the presence or absence of solar radiation. Table 1 shows some of the statistical values for the intensity of the UHI, calculated for the day and night hours.

The intensity calculated from the maximum temperature $\left(I_{\max }\right)$ is representative of the daytime UHI. In general, the daytime UHI displayed negative values, implying the existence of an 'urban cool island' (Montávez et al. 2000). These negative values are a consequence of the rapid daytime heating undergone by the rural landmass as compared with the urban one.

Table 1. Mean, maximum and minimum intensities $I\left({ }^{\circ} \mathrm{C}\right)$ of the Salamanca urban heat island (UHI) for daytime and nighttime hours in 1996. $I_{\max }$ : intensity at the maximum daytime temperature, $I_{\min }$ : intensity at the minimum nocturnal temperature

\begin{tabular}{|ccccc|}
\hline \multirow{4}{*}{ Time $(\mathrm{h})$} & \multicolumn{3}{c|}{$I\left({ }^{\circ} \mathrm{C}\right)$} & Maximum \\
\cline { 3 - 5 } & & Mean & Minimum \\
\hline \multirow{4}{*}{ Nay } & $13: 00$ & -0.1 & 2.7 & -3.7 \\
& $18: 00$ & -0.3 & 5.7 & -4.8 \\
& $I_{\max }$ & -0.9 & 6.5 & -9.9 \\
& $00: 00$ & 1.3 & 6.5 & -4.2 \\
& $07: 00$ & 1.6 & 5.9 & -3.3 \\
& $I_{\min }$ & 1.9 & 7.9 & -4.6 \\
\hline
\end{tabular}

The nocturnal UHI is represented by the intensity calculated from the minimum temperatures $\left(I_{\min }\right)$, since for these temperatures the highest mean positive values for the nocturnal UHI series are reached. The nocturnal UHI was found to have positive mean intensity values. The lesser nocturnal cooling of the urban zone compared to the rural zone is due to the slower rate of emission of the energy accumulated during the day (Wilby 2003). Sometimes, the intensity of the nocturnal UHI reaches negative values. This can be attributed to the prevailing meteorological conditions, mainly the arrival of warm air masses (Kim \& Baik 2004).

\subsection{Seasonal evolution}

The most representative data sets of the daytime and nocturnal UHI are, respectively, the intensities calculated using the maximum $\left(I_{\max }\right)$ and minimum $\left(I_{\min }\right)$ temperatures; thus these data series were considered for the years 1996, 1997 and 1998. A temporal analysis was conducted by season, these being: winter (December to February); spring (March to May); summer (June to August) and autumn (September to November). The mean values of the intensity of the seasonal daytime and nighttime UHI (calculated using $I_{\max }$ and $I_{\text {min }}$ ) can be seen in Table 2 .

The most intense mean sinks of the daytime UHI are seen in spring. As considered for the daily evolution series, this is probably a result of the arrival of more solar radiation and more rapid heating of the ground in the rural zone than in the urban zone. In turn, the highest mean values of the intensity of the nocturnal UHI occur in autumn (Alonso et al. 2003), probably due to a slower nocturnal cooling of the urban ground compared to the rural, together with the high incidence of light winds frequent at this time of the year (La Porte \& Labajo 1983).

\subsection{Annual evolution}

The mean monthly values of daytime $\left(I_{\max }\right)$ and nighttime $\left(I_{\min }\right)$ intensities of the UHI for 1996, 1997 and 1998 are shown in Fig. 2.

During the cold months, the daytime UHI generally shows the highest intensity, decreasing from January to May and increasing from September to December. As in the case of the daily and seasonal evolutions, this may be due to the fact that in these months less solar radiation reaches the ground, such that the daily heating of the rural zone is less intense.

The annual mean and extreme values of the intensity of the daytime and nighttime UHI obtained over the period studied, 1996 to1998, are given in Table 3. 
Table 2. Mean intensity $I\left({ }^{\circ} \mathrm{C}\right)$ of the Salamanca UHI at daytime and nighttime hours for each season in the years 1996 to 1998. Daytime values calculated using the intensity at the maximum daytime temperature $I_{\max }$ nocturnal values calculated using the intensity at the minimum nocturnal temperature $I_{\min }$

\begin{tabular}{|lccccc|}
\hline \multirow{4}{*}{ Year } & \multicolumn{4}{c|}{$I\left({ }^{\circ} \mathrm{C}\right)$} \\
\cline { 3 - 6 } & & Winter & Spring & Summer & Autumn \\
\hline \multirow{4}{*}{ Night } & 1996 & -0.6 & -1.1 & -1.0 & -1.0 \\
& 1997 & -0.9 & -1.6 & -0.8 & -0.4 \\
& 1998 & -0.0 & 0.0 & -0.2 & -0.2 \\
& 1996 & 1.1 & 1.4 & 1.9 & 2.5 \\
& 1997 & 2.0 & 2.7 & 2.9 & 3.5 \\
& 1998 & 3.7 & 3.3 & 3.4 & 3.6 \\
\hline
\end{tabular}

Statistical study of the annual series corresponding to the nighttime UHI suggests the following definitions for Salamanca: a 'weak' island, when the intensity is $<2.0^{\circ} \mathrm{C}$; a 'moderate' island, if the intensity lies between (and including) $2.0^{\circ} \mathrm{C}$ and $4.0^{\circ} \mathrm{C}$, and an 'intense' island when the value is $\geq 4.0^{\circ} \mathrm{C}$.

In Salamanca, maximum annual values of the nighttime UHI are in agreement with the value obtained using the model proposed by Oke (1976) to calculate the maximum intensity reached by the nighttime UHI as a function of the population of the city.

The differences observed in the intensities of the UHI for the 3 yr studied may be due, in part, to the prevailing synoptic conditions during these years, since other factors, such as the morphology of the city or sources of pollution, that might influence the intensity of the UHI varied little from one year to another. In comparing all $3 \mathrm{yr}$, it is also possible to identify inversions in the daytime heat UHI and positive values for the nighttime UHI.
Table 3. Annual mean, daytime $\left(I_{\max }\right)$ and nighttime $\left(I_{\min }\right)$ intensities $\left({ }^{\circ} \mathrm{C}\right)$ of the Salamanca UHI at for the years 1996 , 1997 and 1998

\begin{tabular}{|lcccc|}
\hline & Year & Mean & $I_{\max }$ & $I_{\min }$ \\
\hline Day & 1996 & -0.9 & 6.5 & -9.9 \\
& 1997 & -0.9 & 1.4 & -3.8 \\
& 1998 & -0.1 & 5.9 & -5.5 \\
Night & 1996 & 1.9 & 7.9 & -6.6 \\
& 1997 & 2.9 & 7.8 & -0.6 \\
& 1998 & 3.6 & 9.3 & -3.4 \\
\hline
\end{tabular}

\section{RELATION TO METEOROLOGICAL FACTORS}

The weather is the state of the atmosphere at a given moment and place. In view of the definition of the UHI, it is logical to assume that the weather will affect its intensity. The meteorological variables chosen to study the relationship between the intensity of the UHI and the synoptic situation were wind (both speed and direction), cloudiness, and atmospheric pressure, using values measured at the station at Matacán. Since the most intense UHI was recorded during nocturnal hours, only $I_{\min }$ was considered for this aspect of the study.

\subsection{Wind}

For wind conditions, both speed and direction were considered, although studies conducted by Oke for nighttime UHI in several cities have shown that the most influential meteorological variable affecting the nocturnal UHI is wind speed (Oke 1973; cited in Landsberg 1981).

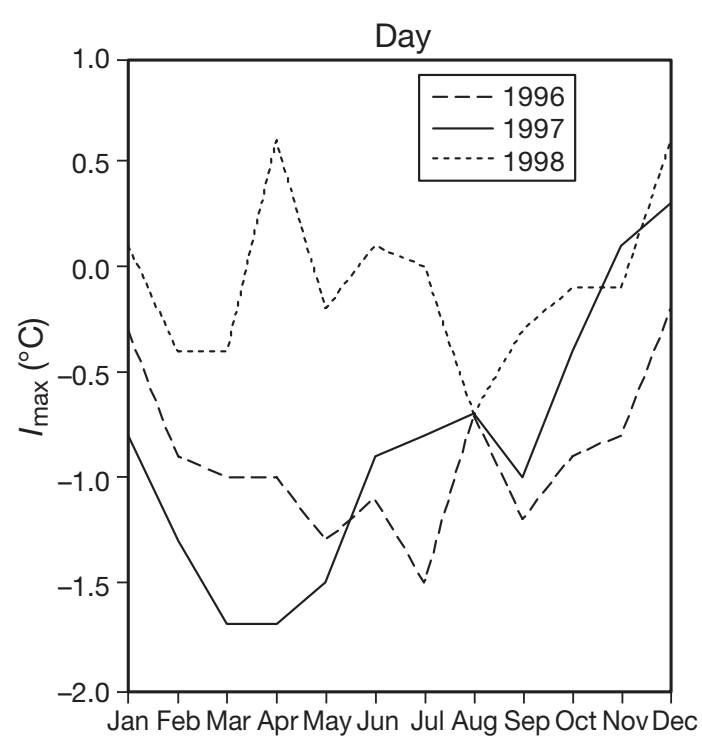

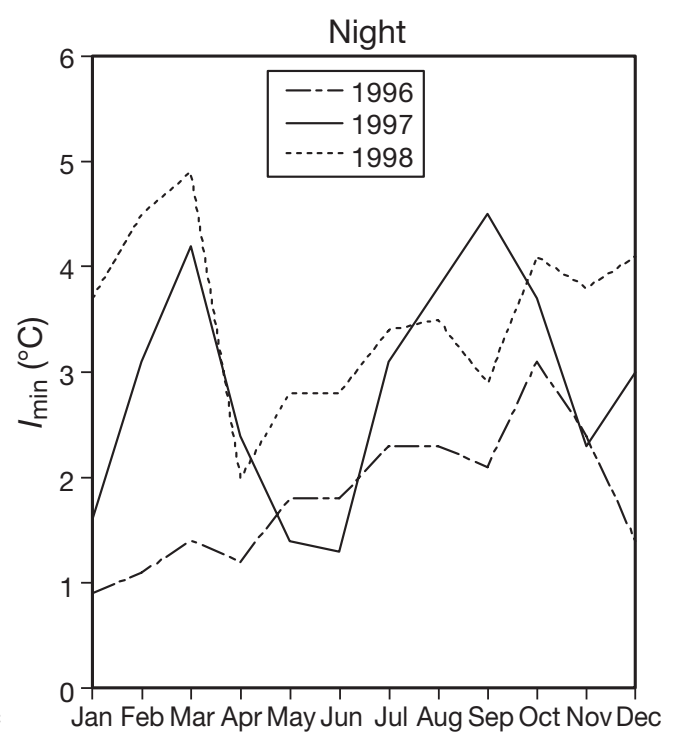

Fig. 2. Mean monthly values of the intensity $I$ $\left({ }^{\circ} \mathrm{C}\right)$ of the Salamanca UHI measured at the maximum daytime temperature $I_{\max }$ and minimum nighttime temperature $I_{\min }$ for the years 1996-1998 
The evolution of the mean monthly intensities of the nocturnal UHI (using $I_{\min }$ ), through 1996 to 1998 compared to the evolution of the mean monthly wind speeds for the same period is shown in Fig. 3. It can be observed that the relative maximum of one of the variables tends to correlate chronologically with the minimum of the other one; this applies to all months. October 1996 showed a maximum UHI intensity; among other causes, this can be attributed to the fact that the mean monthly wind speed during that month was only $0.6 \mathrm{~m} \mathrm{~s}^{-1}$. The opposite case was seen for January 1996, which had a minimum UHI intensity, attributable to the fact that the mean monthly wind speed reached $3.7 \mathrm{~m} \mathrm{~s}^{-1}$. In general, the fact that the annual mean UHI intensity increased from 1996 to 1998 is consistent with changes in the number of hours of light winds.

According to Oke \& Hannel (1970) and Oke (1976), a wind speed - the 'limiting wind speed'-exists for which the intensity of the UHI becomes null. In the case of Salamanca, this speed, which is a function of the population, is close to $6 \mathrm{~m} \mathrm{~s}^{-1}$. From a simple linear regression between the intensity of the nighttime UHI and the daily mean wind speed, it is possible to establish the correlation between both variables (Table 4). Additionally, we gave the intensity of the UHI a value of zero in the regression equation and so obtained a mean value for the limiting wind speed in Salamanca of $6.4 \mathrm{~m} \mathrm{~s}^{-1}$. The linear correlation coefficients (r) between both variables were, as expected, negative. The limiting speed obtained was close to that calculated theoretically with the model of Oke \& Hannel (1970) and Oke (1976).

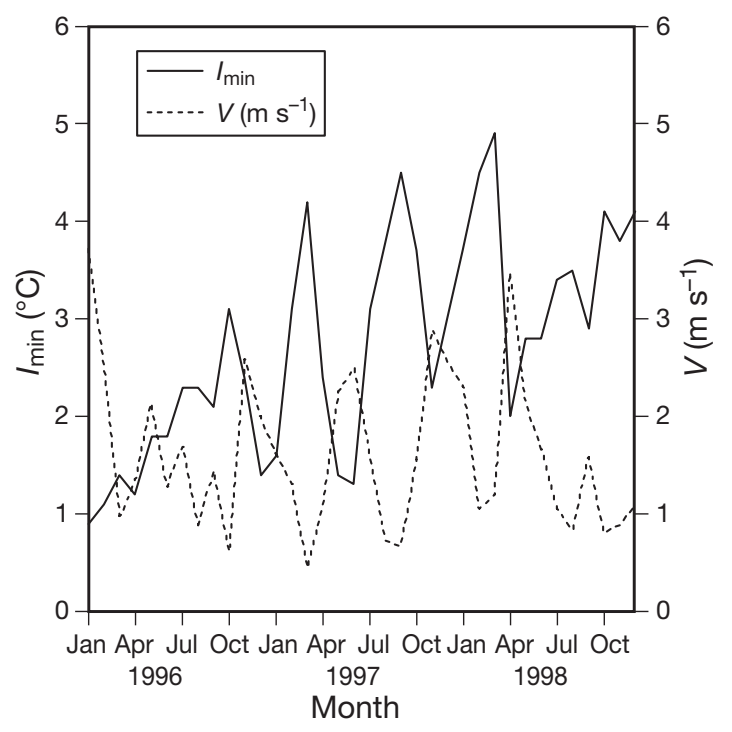

Fig. 3. Mean values of the intensity of the Salamanca UHI at the minimum nocturnal temperature $I_{\min }\left({ }^{\circ} \mathrm{C}\right)$ and avergage values of wind speed $V\left(\mathrm{~m} \mathrm{~s}^{-1}\right)$ for the years 1996-1998
Regarding wind direction, the most frequent longterm mean wind directions in Salamanca correspond to the first (NE) and third (SW) quadrants, with a percentage of calm periods over the year of $21 \%$ (La Porte \& Labajo 1983). Table 5 shows mean values of the intensities of the nighttime UHI, $I_{\min }$, and wind speed at 07:00 h UTC (the time of occurrence of the minimum temperatures with which the intensity of the nighttime UHI are normally recorded) for the most frequent wind profiles (light wind, direction of wind in the first quadrant, and wind direction in the third quadrant).

As expected, the most intense nighttime UHI were associated with light wind situations. Regarding the dominant wind directions, the highest intensity values of the nocturnal UHI were reached when the wind was in the first quadrant; lower values of nocturnal UHI intensity were recorded when the wind was coming from the third quadrant. Moreover, the influence of wind speed on the UHI is confirmed, since normally the wind coming from the first quadrant is less strong than that coming from the third quadrant (Fidalgo 1994).

According to the climatology of Salamanca for the period of 1945-1974 (La Porte \& Labajo 1983), the predominant wind direction throughout the year is the third quadrant, this direction also predominating monthly, with the exception of April and July, when it predominantly comes from the first quadrant. The lowest wind speeds in Salamanca are recorded in autumn, consistent with the finding that the intensity of the UHI is greatest in that season. March has the highest wind speeds, such that the corresponding intensity of the UHI should in general be low. However, the intensities of the UHI in March appear as relative maxima in the annual evolution for the years we studied (Fig. 2). The

Table 4. Regressions between the nighttime Salamanca UHI intensity (measured at the nocturnal minimum temperature $\left.I_{\min }\right)$ and wind speed $(V) . V_{\text {lim }}=$ limiting wind speed

\begin{tabular}{|lccc|}
\hline & $I_{\min }$ & $\mathrm{r}$ & $V_{\lim }\left(\mathrm{m} \mathrm{s}^{-1}\right)$ \\
\hline 1996 & $-0.16 \mathrm{~V}+3.63$ & -0.55 & 6.3 \\
1997 & $-0.18 \mathrm{~V}+4.57$ & -0.55 & 7.1 \\
1998 & $-0.25 \mathrm{~V}+5.81$ & -0.56 & 6.4 \\
1996 to 1998 & $-0.21 \mathrm{~V}+4.80$ & -0.55 & 6.4 \\
\hline
\end{tabular}

Table 5. Mean values of the Salamanca UHI intensity at nocturnal minimum temperature $I_{\min }\left({ }^{\circ} \mathrm{C}\right)$ and mean values of wind velocity at 07:00 $\mathrm{h}$ (I) $V_{7}$ for the most frequent wind profiles 1996-1998

\begin{tabular}{|lcr|}
\hline & $I_{\min }$ & $V_{7}$ \\
\hline Light wind & 3.7 & 0.0 \\
1st Quadrant & 2.6 & 7.5 \\
3rd Quadrant & 1.4 & 12.4 \\
\hline
\end{tabular}


probable reason for this is that for these years the March wind speed was low, with a large number of hours of light winds.

\subsection{Cloudiness}

To study the relationship between cloudiness and the intensity of the nighttime UHI, the cloudiness recorded at 13:00 h UTC at Matacán for the 3 yr period 1996 to 1998 was used. This variable was employed because the greatest amount of solar radiation reaches the ground at midday. The joint monthly evolution of $I_{\min }$ with the number of clear days (0 eighths [0/8] of cloud cover) per month is shown in Fig. 4a. The evolution of the nocturnal UHI together with the number of cloudy days (8/8 cloud cover) is shown in Fig. $4 \mathrm{~b}$.

These plots indicate a positive relationship between the intensity of the nighttime UHI and the number of clear days and a negative relationship with the number of cloudy days, i.e. the maximum intensity generally coincides with the maximum number of clear days and in turn the minimum intensity generally coincides with the minimum of cloudy days.

We next considered only the days on which the wind was light, for the 07:00 h UTC observation, with a view to removing the influence of the wind from the cloud relationship. Clear days and those of $1 / 8,2 / 8$ or $3 / 8$ cloudiness were considered separately. Table 6 shows the mean values of the intensities of the nighttime UHI $\left(I_{\min }\right)$ according to cloudiness for 1997 and 1998; the number of days considered in each case is also shown.

It can be seen that the mean intensity of the nighttime UHI decreases as cloudiness increases, although when the latter reaches $3 / 8$ of clouded sky the UHI intensity increases again, but never up to the intensity obtained with cloudless sky. An explanation for the increase in the intensity of the UHI when a value of $3 / 8$ of cloudiness is reached can be found in the type of cloud present. The mean intensity of the UHI was calculated as a function of the type of cloud covering. During the period studied we considered only low clouds and high clouds because, in principle, they can be considered as the most influential as regards the energy received at the ground (Labajo et al. 1988). The results are shown in Table 7.

In all cases, the intensity of the nighttime UHI was greater when the predominant clouds were high, suggesting that low clouds absorb more solar radiation than high ones. Moreover, high clouds, especially $\mathrm{Cc}_{\text {, }}$ may allow up to $20 \%$ more radiation to reach the ground than low clouds (Labajo et al. 1988). This could explain why for a cloud cover of 3/8 formed by cirrus-like clouds, the intensity of the UHI is greater than with a $2 / 8$ cover formed by clouds of other types.

To conclude the study, we simultaneously considered the effect of wind speed and cloudiness. First, we removed the cases with light winds and winds whose speeds were greater than $6.1 \mathrm{~m} \mathrm{~s}^{-1}$ (the theoretical limiting speed in Salamanca-see Section 4.1). We then calculated the mean intensity of the nighttime UHI for those days according to cloudiness. The results are shown in Table 6b. If the wind is considered, the mean value of the intensity of the nocturnal UHI decreases. These results are in agreement with those reported by other authors for larger cities (Morris et al. 2001).
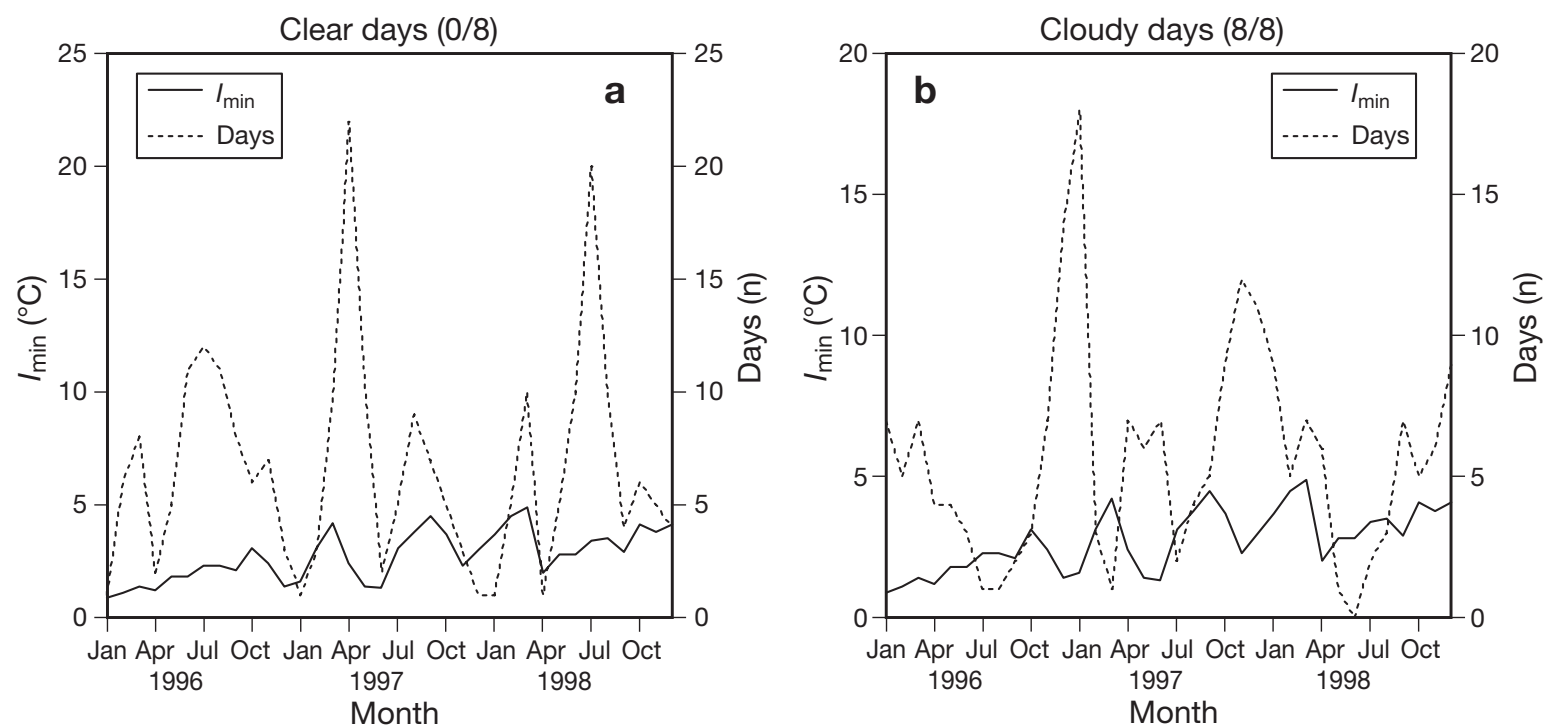

Fig. 4. Mean values of the intensity of the Salamanca UHI at the minimum nocturnal temperature $I_{\min }\left({ }^{\circ} \mathrm{C}\right)$ and the number $(\mathrm{n})$ of: (a) clear days (0/8 cloud cover); and (b) cloudy days (8/8 cloud cover) for the years 1996-1998 
Table 6. Mean values of the Salamanca UHI intensity at nocturnal minimum temperature $I_{\min }\left({ }^{\circ} \mathrm{C}\right)$ for the years 1997 and 1998 according to cloudiness and wind speed. Low wind speed: $0<V_{7}<6.3 \mathrm{~m} \mathrm{~s}^{-1}$. $\mathrm{n}=$ no. of days

\begin{tabular}{|lcccc|}
\hline \multirow{2}{*}{ Cloud cover } & \multicolumn{3}{c}{ All wind speeds } & \multicolumn{2}{c|}{ Low wind speeds } \\
& $I_{\min }$ & $\mathrm{n}$ & $I_{\min }$ & $\mathrm{n}$ \\
\hline $0 / 8$ & 4.5 & 62 & 3.9 & 25 \\
$1 / 8$ & 4.2 & 52 & 3.0 & 22 \\
$2 / 8$ & 3.5 & 61 & 2.4 & 20 \\
$3 / 8$ & 4.4 & 38 & 2.6 & 18 \\
\hline
\end{tabular}

Table 7. Mean values of the Salamanca UHI intensity at nocturnal minimum temperature $I_{\min }\left({ }^{\circ} \mathrm{C}\right)$ according to the type of cloud (low or high) and the cloud cover (1/8 to $3 / 8)$ for the years 1997 and 1998. $n=$ number of days

\begin{tabular}{|lccc|}
\hline Cloud cover & Cloud type & $I_{\min }$ & $\mathrm{n}$ \\
\hline $1 / 8$ & Low & 3.7 & 35 \\
& High & 5.3 & 17 \\
$2 / 8$ & Low & 3.0 & 36 \\
& High & 4.0 & 25 \\
$3 / 8$ & Low & 3.7 & 13 \\
& High & 4.8 & 25 \\
\hline
\end{tabular}

\subsection{Synoptic pressure conditions}

An anticyclonic situation implies a settled atmosphere with light wind conditions and cloudless skies. However, a low atmospheric pressure situation implies an unsettled atmosphere. To study the relationship between the intensity of the nocturnal UHI and atmospheric pressure, the synoptic conditions of a few days in 1996, 1997 and 1998 were used.

It is evident that days with an intensity of the UHI higher than its annual mean value are associated with anticyclonic situations over the Iberian Peninsula. As an example, we show the surface synoptic map for 29 July 1998 (Fig. 5), when wind was light and skies cloudless. The intensity of the nighttime UHI was $7.8^{\circ} \mathrm{C}$.

In contrast, if a day with an intensity of UHI lower than annual mean value is considered, low atmospheric pressure over the Iberian Peninsula is observed. This occurred for example, on 4 March 1998 (Fig. 6), which had a nighttime UHI intensity of only $1.1^{\circ} \mathrm{C}$. The weather conditions on this day were high wind speed (8 $\mathrm{m} \mathrm{s}^{-1}$ at 07:00 h UTC) and 3/8 cloud cover.

\section{CONCLUSIONS}

Although the UHI is a well-established phenomenon, previous studies have focused on large, nonEuropean cities. Understanding how the UHI operates in different regions is important. Here, the UHI in the
Spanish city of Salamanca-characterised by a very large seasonal temperature cycle-is investigated for the first time. Also novel is the particular emphasis given to the relationship between UHI intensity and cloudiness.

The daily evolution of the UHI in this medium-sized European city is shown to display 2 clearly differentiated situations: on the one hand, the daytime UHI shows negative mean values, which gives rise to the so-called 'urban cool island', in particular caused by the rapid heating undergone by the rural zone when receiving solar radiation (López et al. 1993, Figuerola \& Mazzeo 1998). In the city of Salamanca, the strongest daytime urban cool island occurs in spring. On the other hand, there is a nighttime UHI with positive mean annual values, and this is the result of the slower nocturnal cooling undergone by the urban zone. The highest mean intensities of the nighttime UHI in Salamanca are reached in autumn when, according to the long-term climatology of the city, the wind speeds are lowest.

The following classification of the nighttime UHI intensity in Salamanca has been established: weak

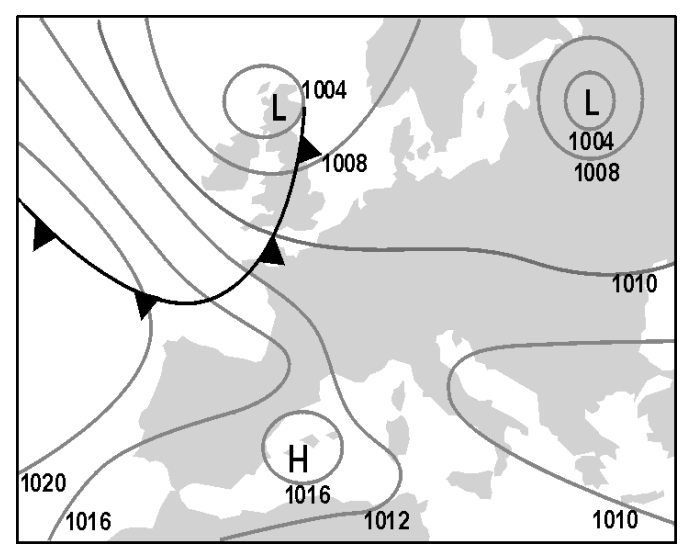

Fig. 5. Synoptic conditions on 29 July 1998 at 12:00 h UTC

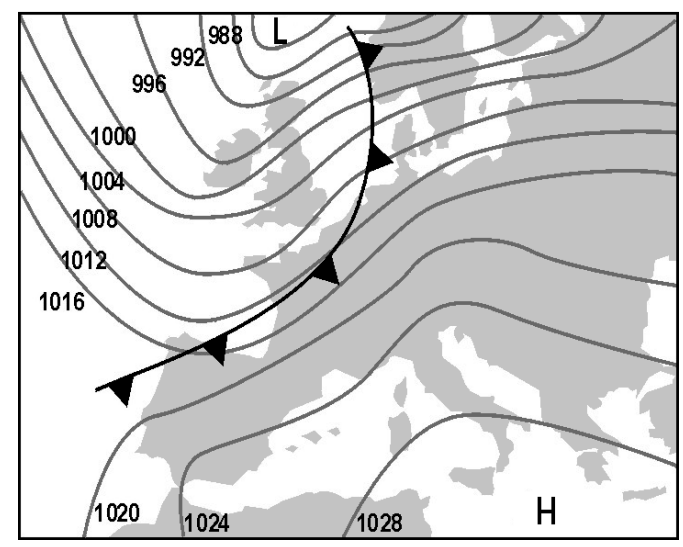

Fig. 6. Synoptic conditions on 4 March 1998 at 12:00 h UTC 
island (lower than $2.0^{\circ} \mathrm{C}$ ); moderate island (between $2.0^{\circ} \mathrm{C}$ and $4.0^{\circ} \mathrm{C}$ ), and intense island (greater than $\left.4.0^{\circ} \mathrm{C}\right)$.

The intensity of the UHI shows temporal variations that, in general, are due to the prevailing meteorological situation. Those with the greatest influence in the UHI are considered to be wind, cloudiness and synoptic pressure conditions.

The wind speed negatively affects the intensity of the UHI and even abolishes it when a limiting value is reached. In the case of Salamanca, the limiting speed is $6.4 \mathrm{~m} \mathrm{~s}^{-1}$, calculated from the mean daily wind speed data and consistent with theoretical estimates. The direction of the wind, i.e. of the general flow, prevailing over Salamanca is from the first and third quadrants. The mean intensity of the UHI is higher for the cases of the first quadrant since this is associated with the lowest wind speeds. However, the most intense nighttime UHI are associated with light wind, a conclusion that can be extrapolated to any medium-sized city, whatever its predominant wind direction.

In general, cloudiness causes the intensity of the UHI to decrease, unless there is a predominance of high clouds, in which case the intensity of the nighttime UHI increases.

Regarding synoptic pressure conditions, anticyclonic situations imply atmospheric stability that favours the establishment of more intense UHI, whereas situations of atmospheric instability lead to decreases in the intensity of UHI.

The phenomenon of urban heating may by altered by changing the structure of the city, in particular by adding green zones in the city centre, where heating is usually accentuated (Upmanis et al. 1998). Understanding the intensity and variability of the UHI and its relationships with meteorological variables, particularly with cloudiness, is an essential first step prior to implementing and monitoring such remedial measures and also for assessing how the UHI might change in the future, for example, in response to enhanced greenhouse warming.

\section{LITERATURE CITED}

Alonso MS, Labajo JL, Fidalgo MR (2003) Characteristics of the urban heat island in the city of Salamanca, Spain. Atmósfera 16:137-148

Fidalgo MR (1994) El Clima: fichas de diagnóstico de salud. Ayuntamiento de Salamanca, Salamanca

Fidalgo MR, Mateos J, Garmendia J (1988) The origin of some

Editorial responsibility: Clare Goodess,

Norwich, UK elements contained in the aerosols of Salamanca (Spain). Atmos Environ 22:1405-1498

Figuerola P, Mazzeo N (1998) Urban-rural temperature differences in Buenos Aires. Int J Climatol 18:1709-1723

García F (1996) Manual de climatología aplicada. Clima, medioambiente y planificación. Síntesis, Madrid

Hänel G, Busen R, Weidert D (1990) Absorption of solar radiation in an urban atmosphere. Atmos Environ B 24: 283-292

Hoyano A, Lino A, Ono M, Tanighchi S (1999) Analysis of the influence of urban form and materials on sensible heat flux, a case study of Japan's largest housing development, Tama New Town. Atmos Environ 33:3931-3939

Jáuregui E (1988) Local wind and air pollution interaction in the Mexico basin. Atmósfera 1:131-140

Kim YH, Baik JJ (2002) Maximum urban heat island intensity in Seoul. J Appl Meteorol 41:651-659

Kim YH, Baik JJ (2004) Daily maximum urban heat island intensity in large cities of Korea. Theor Appl Clim 79: $151-164$

Labajo JL, Labajo A, Labajo S, Izquierdo MJ (1988) Influencia de las nubes altas en el flujo de la radiación solar global. Rev Geofísica 44:61-68

Landsberg HE (1981) The urban climate. Academic, New York

La Porte P, Labajo JL (1983) El clima de Matacán (Salamanca). INM A-74. Instituto Nacional de Meterologìa, Madrid

López A, Lopez J, Fernandez F, Moreno A (1993) El clima urbano: teledetección de la isla de calor en Madrid. MOPT, Madrid

Montávez JP, Rodríguez A, Jiménez JI (2000) A study of the urban heat island of Granada. Int J Climatol 20:899-911

Moreno-García C (1994) Intensity and form of the urban heat island in Barcelona. Int J Climatol 14:705-710

Morris CJG, Simmonds I (2000) Associations between varying magnitudes of the urban heat island and the synoptic climatology in Melbourne, Australia. Int J Climatol 20: 1931-1954

Morris CJG, Simmonds I, Plummer N (2001) Quantification of the influences of wind and cloud on the nocturnal heat island of a large city. J Appl Meteorol 40:169-182

Oke TR (1976) The distinction between canopy and boundary layer urban heat islands. Atmosphere 14:268-277

Oke TR, Hannel FG (1970) The form of the urban heat island in Hamilton, Canada. WMO Tech Note 108:113-126

Sahashi K, Hieda T (1996) Nitrogen-oxide layer over the urban heat island in Okayama City. Atmos Environ 30: $531-535$

Saitoh TS, Hoshi H (1992) Urban warming in Tokyo metroolitan area. International Conference on Thermal Environment (CUTEST'92), Fukuoka, p 11-17

Sundborg A (1950) Local climatological studies of the temperature conditions in an urban area. Tellus 2:222-232

Unger J, Sümeghy Z, Zoboki J (2001) Temperature crosssection features in an urban area. Atmos Res 50:117-127

Upmanis H, Eliasson I, Lindsquist S (1998) The influence of green areas on nocturnal temperatures in a high latitude city (Göteborg, Sweden). Int J Climatol 18:681-691

Wilby RL (2003) Past and projected trends in London's urban heat island. Weather 58:251-260

Submitted: December 18, 2002; Accepted: April 15, 2006

Proofs received from author(s): May 13, 2007 